\title{
What Is the Right Way to Structure Global Health? The Case for Radical New Organisations and Thinking
}

\author{
Lord Jim O’Neill
}

\begin{abstract}
COVID-19 has exposed deep weakness in the governance of global health. Lessons can be learned for the reform of global public health from the 'Global Review Into Antimicrobial Resistance (AMR)' that was created by Prime Minister David Cameron in the UK in 2014. The core problem of AMR is both a supply and demand problem. From a supply perspective, there is a lack of development of new useful antimicrobials. Fundamentally, the financial returns are not perceived to be suitably high for complex path of bringing new antibiotics to market. From a demand perspective, modern society has an excessive use of existing antibiotics, which is causing many of them to lose their ability to work as the microbes adapt and mutate to evade the effectiveness of treatments. The abuse is not just in humans. In many parts of the world, most definitely within the US, the use of antibiotics in animals is higher than in humans. If a solution to antibiotic abuse cannot be found, then by 2050, there could be as many as 10 million people a year dying from AMR-related illnesses. The COVID-19 pandemic has proved that there are massive economic and financial costs from global health threats when not met by fast robust actions.
\end{abstract}

Keywords COVID-19 has exposed deep weakness in the governance of global health • 'Global Review Into Antimicrobial Resistance (AMR)' - There is a lack of development of new useful antimicrobials - Modern society has an excessive use of existing antibiotics $\cdot$ The use of antibiotics in animals is higher than in humans $\cdot 10$ million people a year could die from AMR-related illnesses - Massive economic and financial costs from global health threats

\section{What Is the Right Way to Structure Global Health?}

In trying to answer this question, I immediately think it is important to recall that frequently, future major challenges are often different than the one we are trying to deal with at the moment. In this regard, while it seems quite likely that COVID-19 will not be the last pandemic the world faces, it might well be that through all the

J. O’Neill (凶)

Royal Institute for International Affairs, London, UK 
reactive responses to this crisis, it will stand the world, and many parts of it, in much better shape the next time we do face a major global health challenge.

\section{Lessons Learned from Antibiotic Abuse}

However, notwithstanding this observation, I reflect on my own experience of chairing the independent 'Global Review Into Antimicrobial Resistance (AMR)'. I was invited to chair the AMR Review by Prime Minister David Cameron for the government in the UK in 2014. Out of the AMR Review experience, I have a number of ideas that might allow the world to be better placed, especially from an economic and financial perspective.

When I was asked to lead the AMR Review, many observers, not least me, were somewhat surprised that an economist with little formal training in health or science was asked to lead it. By the time I had spent a couple of months in the role, I quickly realised why it had been an imaginative idea, and one that would at least allow the issues to be considered in a different, probably broader framework.

I recall joking with the then UK Chief Medical Officer, Dame Sally Davies, that the specialist health scientists knew so much about AMR — and so it was not clear why anyone was needed to bring more ideas. I did this partially to make it clear that I was going to stick to my own experience and training and analyse the issues from an economic perspective, especially an international one. Which I did, and this is how I will reflect on COVID-19 in this essay.

The core problem of AMR is both a supply and demand problem, when considered in economic terms. From a supply perspective, there is a lack of development of new useful antimicrobials in existence, or useful alternatives such as relevant vaccines or other alternative treatments.

Fundamentally, the financial returns are not perceived to be suitably high for the long and often complex path of bringing new antimicrobials, especially antibiotics to market. Potential producers, usually major pharmaceutical companies, have higher returns on offer from a variety of other products.

From a demand perspective, modern society has an excessive use of existing antibiotics, which is causing many of them to lose their ability to work as the microbes adapt and mutate to evade the effectiveness of treatments. As I have often said, society has to stop wanting to treat antibiotics like sweets or candy. The outcome is that antibiotics are often misused.

One example is in treating viral infections, with sore throats being a particularly good illustration. The abuse is not just in humans. In many parts of the world, most definitely within the USA, and probably China, the use of antibiotics in animals is higher than in humans, and often in the case of animals, the use of antibiotics is inappropriate. It has become a belief that antibiotics are useful for growth promotion and as a health preserving tool in intensive animal farming. The problem has become so acute in some areas, that so-called last in line antibiotics, critical for helping humans fight illness when other antibiotics would not work, are losing their power. 
The example of Colistin, and its overuse in cows in China, is a much-discussed recent example. There is a great deal to be done-but, I was glad to note an analytical paper in the Lancet in October 2020 titled, 'How China is getting its farmers to kick their antibiotic habit'.

To solve the problem of AMR, we need to try and boost the supply of useful antimicrobials while at the same time reducing the demand. Of course, this simultaneous challenge adds to the complexity, because the potential producers, as in most areas of business, are naturally attracted to selling as much of a product as possible at the highest attainable prices. But what society needs is precisely the contrary when it comes to the role of antimicrobials. What the world needs is a lot of potential supply, but at affordable prices - and not an overuse.

In the middle of this challenge is the reality that in many parts of the developing world there remains a huge challenge of any access, never mind excess. Many of these challenges are pertinent to the current pandemic, which I shall turn to shortly.

One of the major reasons why our AMR Review became so well known is our predictions of millions of human deaths. We suggested that, if a solution to antibiotic abuse could not be found, that by 2050 there could be as many as 10 million people a year dying from AMR-related illnesses. That number was up from around 700,000 deaths we discovered could be identified in 2015. Around a third of these deaths alone would be in the emerging world as a result of drug-resistant TB.

Indeed, this research taught me that one of the major shared threats that Brazil, Russia, India, China and South Africa, the so-called BRICS countries, face is that they all had a major challenge with TB, and therefore drug-resistant TB. This means it would be in the shared interests of the BRICS nations to find new useful drugs or vaccines.

In other spheres of life, illnesses like sepsis and gonorrhoea are already major problems, and if we do not solve this problem, then many treatments that have become common place in our lifetimes, such as hip replacements or eye cataract surgery will become impossible. We simply will not have antibiotics to treat the infections that are a side consequence of such routine operations. Because of all of this, we also showed that the potential accumulated loss of economic activity for the world could be a colossal USD 100 trillion from 2015 through 2050.

Our AMR Review became known for these two numbers alone, potentially 10 million deaths a year and a USD 100 trillion in foregone economic output. We derived 29 different interventions for the world that would ensure this problem would be solved.

A few observers commented that the likely cost of our AMR Review forecasts would not be anything as high as this. We responded by saying that yes, these and similar forecasts are merely forecasts, but it was equally possible that the costs could be higher, potentially much higher. 


\section{The Massive Economic and Financial Costs from Global Health Threats-New Ideas to Offset}

One thing that this COVID-19 pandemic has surely proved is that there are massive economic and financial costs from global health threats when not met with fast, robust actions. It is probably the case that global real GDP declined somewhere in the vicinity of $4 \%$ in 2020 , which is more than four times larger than the decline in 2008.

I think many people now realise the challenges of health are embedded in our economic and financial lives. Because of this reality, here are the major ideas that I consider necessary - although I repeat my opening comment that some aspects of this crisis will probably automatically lead to a more robust system in the future.

One of the biggest economic and financial challenges the world now faces is, apparently, the huge size of debt, especially that of many governments, and with it, what, if anything, to do about it. Most conventional thinkers believe that as soon as our economies are robust enough, governments will have to start tightening fiscal policy through either spending cuts or tax increases, or a combination of both. This might be, indeed, necessary.

But an alternative, more radical and imaginative way of thinking about this, could be a revamp of how we account for government spending. In particular, I believe we might want to split total government spending - past, present and future-into investment spending and consumption, or maintenance and spending.

Investment spending should create future growth especially for the private sector, often with a large multiplier impact. Consumption spending, especially when it is used to maintain systems, does not and should be treated differently. If we want the latter, maybe tax-payers should be prepared to pay more, whereas the former would create growth in the future and might not need to be paid for now.

This is all hugely relevant for a better domestic health system. Too often, and generally from an accounting perspective, health spending is budgeted as one overall system. But how can government investing in support of new antibiotics, vaccines, or diagnostics, or genomics and so on, be regarded as the same as paying the wages and salaries of more doctors and nurses? The former may be central to stopping any future major diseases, while the latter is primarily done to respond to ongoing health management. It is crazy to treat them as the same from an accounting perspective, and this is often why crucial investments that only pay off in the future get postponed, delayed, cancelled or often not approved at all, especially in democracies.

\section{Reform of Global Agencies-The IMF}

Another obvious issue that became clear to me after our AMR Review finished, and is dramatically clearer even now post COVID-19, is the role of the IMF. Generally, since its creation after World War Two, the IMF has sat at the heart of global 
economic management and for much of the time focused on traditional macroeconomic goals, including the classic macroeconomic challenges of economic growth, inflation, unemployment, and especially, balance of payments stability. It was not until the Asian financial crisis in 1997 that the IMF began to focus on financial sector stability. Of course, as a result of the 2008 financial crisis, and its consequences, the IMF now regards financial stability as a major part of its remit and usefulness.

In more recent years, the IMF has started to engage on aspects of the battle against climate change, not least of which is because of the potential consequences for macroeconomic stability. But talk to senior people at the IMF before this pandemic, about the need for them to opine more about health systems, and they quickly shy away, saying they have neither expertise nor remit. Surely this is ridiculous. If a global pandemic has been responsible for the loss of circa USD 10 trillion to the world economy, how can the IMF not only want, but avoid the need to understand global health? I had previously articulated the need for the IMF to start offering judgement on member country health systems as part of their Article IV series, and I now believe it is unavoidable. The IMF's Article IV is something that financial markets respect, not least because it is also something ratings agencies respect, and by incorporating an opinion about member country health systems would make it a lot more likely that countries would want to start investing more to improve health systems. In this regard, what about how specific decisions might be made about health spending, both within and across countries?

\section{Government Health Spending-The Need to Revamp Accounting Principles}

Once more, thinking as an economist, I default immediately to the distinction between investments and consumption. During the period just prior to accepting the role of chairing the AMR Review from 2014 through 2020, the UK proudly showed that the risks of pandemics and AMR were prominent in its national risk register, something that the country appeared to be admired for around the world.

When it came to the crunch, and walking the walk, as opposed to talking the talk, it did not seem to be especially useful. As is well known, at least during the 2020 period of the pandemic, the UK suffered more than most when it came to lives lost and the economic consequences. There are many reasons, some of which we still are yet to learn, but chief amongst them is that Public Health England (PHE), the body established to identify best practices, was clearly not up to scratch when it came to the vital role of testing our citizens for COVID-19 and the whole test and trace system failed dramatically to help ward off the spread in early 2020, which on many levels the UK has been trying to make up for ever since.

And while the UK has seemingly excelled so far in both the discovery of new vaccines and based on early 2021 evidence, their rollout, the financing that the UK commits to these vital aspects of the solution are generally stuck in the same bucket 
of finance as spending on hospitals. It is also the case that the UK's contribution to treatments, diagnostics and vaccines for lower income countries was part of its, only just recently, dismantled Department for International Development (DFID). Why would it not be seen as part of overall health investment spending for the world, alongside its investment spending on health internally?

Then below this set of prioritisations on health investments, what financial tools are being supported to offer as incentives? For example, to universities, the private commercial health sector and others, so that they have an ongoing motivation for the development of new useful vaccines, antibiotics and such. It is crucial that when the next global shock hits, we are in a position to escalate this research immediately.

In the parlance of the health incentives, have we got the appropriate portfolio of push and pull incentives in place? As it happens, the UK appears to have probably been in a better position than most, partly because of its leading universities, and the coincidence that it is home to two major international pharmaceutical companies. But certainly, for example, as it relates to antibiotics and AMR today in 2021, the UK does not have the right set of tools to ensure confidence of its future antibiotic supply.

\section{Matching the Role and Responsibilities of the World Health Organisation (WHO) with Global Reality}

Returning to the international arena and systems of governance, we should address the question of whether the much criticised WHO is fit for its purpose? As part of any fair answer to this question, I find myself quickly thinking, is it set up for modern effective purpose? Do its members really allow for the WHO to call out its member countries about the quality of their health systems?

Moreover, while it has rightly become the parlance to think in terms of 'One Health' which includes all animals, plants and the natural world, as well as humans, why do we have separate entities to preside over each of these?

How can the WHO realistically be expected to stop the threat of AMR or future pandemics, if the responsibilities for animals rests with the Food and Agriculture Organisation (FAO) and not the WHO? While it is fashionable in some quarters to call out the WHO about the source of the COVID-19 pandemic in China, what powers did they really have, since, as most experts seem to believe, it originated in a live animal food market?

Such thinking leads immediately to the idea that perhaps we need a 'One Health' organisation in which the WHO, the FAO and the World Organisation for Animal Health (OIE) are all merged into one. This has a compelling logic if we are going to genuinely have a better global system to cope with future threats. Of course, such an idea raises all sorts of fears about bumbling bureaucracies, but this should not automatically equate to having the best framework. I, for one, believe this is something that needs to be given serious consideration. Post the high level UN 
agreement that was successfully achieved to combat AMR in September 2016, it was agreed also to proceed with an interagency agreement between the WHO, FAO and OIE about cooperation on AMR, but as far as I have observed, nothing specific has been achieved. Nothing has been done to embed some new ideas or principles as to how, in practise, this relates to managing our planet better in terms of health and prosperity. Of course, some might say, if this step of cooperation is proving to be too challenging what chance would there be of success to a whole new organisation, tasked with such ambition? My answer to this is, do we want to have positive ambition or not?

Obviously, it is very clear the WHO needs to work better regardless of the future institutional arrangements and a number of functions in this regard are equally vital. But unless the WHO is itself is tasked to have a chance of dealing with the threats we face, even this would not mean much.

\section{Lessons for Global Healthcare Reforms from the 2008 Global Financial Crisis}

Another idea I have been influenced about comes also from learning from the 2008 crisis-including the policy response to that crisis. One of the major, albeit, less discussed consequences was the establishment of the Financial Stability Board (FSB) under the auspices of the Group of 20 (G20). The awakening of the G20 in itself was a major positive consequence of the crisis in my view, not least because it brought to the centre of world economic policymaking a stronger legitimate representative group of the world than others that preceded it. This was not least because of the inclusion of China, the other BRICS countries, as well as other emerging economies that matter for tackling truly global challenges. This should not be forgotten in the current times where a mood of us versus them seems to frequently dominate many people's thinking.

Under the G20, the FSB has played a solid role, sometimes below the radar, in ensuring a stronger global financial system that allows for better capitalisation of major global financial institutions, amongst other things. Judging by-at least so far - the stability of the major financial sectors through this pandemic, this has been quite a successful achievement.

\section{Creating a Global Stability Structure to Focus on Global Public Goods}

In this context, I am minded to propose an additional or broader body to the FSB, to be specific, one that is tasked with a focus on global public goods, one central part of which is health. 
Just as in the 2008 crisis, COVID-19 has demonstrated the centrality of global finance to the lives of all seven billion of us, and the establishment of the FSB has seemingly made the system more resilient. The reality is we need the same body to protect the interests of even broader societal goals, including combating climate change, health and perhaps education. And certainly, within the focus on health, the early monitoring of pandemics and other global disease threats including AMR must be treated with the same respect we now treat the threat of financial disruption.

\title{
9 Harmonising the Objectives of Business with the Needs of Global Public Goods
}

\begin{abstract}
Above all of this, I have one remaining overall observation and takeaway from this crisis, which concerns the state of global capitalism, including the circumstances in which this crisis occurred.

I have often said that leading the AMR Review has perhaps been the most stimulating professional experience I have been lucky enough to have had. Amongst the many reasons I say this is that it taught me that the way the international economic system has evolved during my lifetime has, if not directly created, certainly contributed to considerable global societal challenges.

However, many of the actors in the system do not seem to regard it being their responsibility to help solve global societal challenges. I fundamentally disagree with this avoidance of responsibility. I believe all of us get our licence to operate in our business lives from the societies we inhabit.

In this regard, I believe the sometimes apparent near obsession with profit maximisation has to evolve to an era where the role of business is to optimise its objectives, of which profit attainment is crucial, but not the only one.

Without such a shift in mentality, I fear that once we have beaten this COVID-19 crisis, we may default back to a usual way of life and forget some of the powerful moments of thought this crisis has forced upon us.
\end{abstract}

Lord Jim O'Neill was Chairman of the Royal Institute International Affairs (Chatham House) for three years up until July 2021. Jim worked for Goldman Sachs from 1995 until 2013, spending most of his time there as chief economist. Jim is also the creator of the acronym 'BRIC' and has conducted much research about these and other emerging economies and published various books on the topic. Between 2015 and 2016, he was Commercial Secretary in the British Government working with Chancellor George Osborne. He also led an independent review into antimicrobial resistance (AMR) for UK Prime Minister David Cameron from 2014 to 2016, and remains focused on this challenge. 
Open Access This chapter is licensed under the terms of the Creative Commons AttributionNonCommercial-NoDerivatives 4.0 International License (http://creativecommons.org/licenses/bync-nd/4.0/), which permits any noncommercial use, sharing, distribution and reproduction in any medium or format, as long as you give appropriate credit to the original author(s) and the source, provide a link to the Creative Commons license and indicate if you modified the licensed material. You do not have permission under this license to share adapted material derived from this chapter or parts of it.

The images or other third party material in this chapter are included in the chapter's Creative Commons license, unless indicated otherwise in a credit line to the material. If material is not included in the chapter's Creative Commons license and your intended use is not permitted by statutory regulation or exceeds the permitted use, you will need to obtain permission directly from the copyright holder.

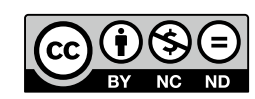

